\title{
The Arctic and Subarctic Ocean Flux of Potential Vorticity and the Arctic Ocean Circulation*
}

\author{
JIAYAN YANG \\ Department of Physical Oceanography, Woods Hole Oceanographic Institution, Woods Hole, Massachusetts
}

(Manuscript received 29 September 2004, in final form 16 May 2005)

\begin{abstract}
According to observations, the Arctic Ocean circulation beneath a shallow thermocline can be schematized by cyclonic rim currents along shelves and over ridges. In each deep basin, the circulation is also believed to be cyclonic. This circulation pattern has been used as an important benchmark for validating Arctic Ocean models. However, modeling this grand circulation pattern with some of the most sophisticated ocean-ice models has been often difficult. The most puzzling and thus perhaps the most interesting finding from the Arctic Ocean Model Intercomparison Project (AOMIP), an international consortium that runs 14 Arctic Ocean models by using the identical forcing fields, is that its model results can be grouped into two nearly exact opposite patterns. While some models produce cyclonic circulation patterns similar to observations, others do the opposite. This study examines what could be possibly responsible for such strange inconsistency. It is found here that the flux of potential vorticity (PV) from the subarctic oceans strongly controls the circulation directions. For a semienclosed basin like the Arctic, the PV integral over the whole basin yields a balance between the net lateral PV inflow and the PV dissipation along the boundary. When an isopycnal layer receives a net positive PV through inflow/outflow, the circulation becomes cyclonic so that friction can generate a flux of negative PV to satisfy the integral balance. For simplicity, a barotropic ocean model is used in this paper but its application to the 3D models will be discussed. In the first set of experiments, the model with a realistic Arctic bathymetry is forced by observed inflows and outflows. In this case, there is a net positive PV inflow to the basin, due to the fact that inflow layer is thinner than that of outflow. The model produces a circulation field that is remarkably similar to the one from observations. In the second experiment, the model bathymetry at Fram Strait is modified so that the same inflows and outflows of water masses lead to a net negative PV flux into the Arctic. The circulation is reversed and becomes nearly the opposite of the first experiment. In the third experiment, the net PV flux is made to be zero by modifying again the sill depth at Fram Strait. The circulation becomes two gyres, a cyclonic one in the Eurasian Basin and an anticyclonic one in the Canada Basin. To elucidate the control of the PV integral, a second set of model experiments is conducted by using an idealized Arctic bathymetry so that the PV dynamics can be better explained without the complication of rough topography. The results from five additional experiments that used the idealized topography will be discussed. While the model used in this study is one layer, the same PV-integral constraint can be applied to any isopycnal layer in a threedimensional model. Variables that affect the PV fluxes to this density layer at any inflow/outflow channel, such as layer thickness and water volume flux, can affect the circulation pattern. The relevance to 3D models is discussed in this paper.
\end{abstract}

\section{Introduction}

The Arctic Ocean is a semienclosed basin covered by sea ice. It is connected with the Pacific Ocean through

* Woods Hole Oceanographic Institution Contribution Number 11373.

Corresponding author address: Jiayan Yang, Department of Physical Oceanography, Woods Hole Oceanographic Institution, Woods Hole, MA 02543.

E-mail: jyang@whoi.edu
Bering Strait and with the Nordic Seas through Fram Strait and the Barents Sea. Inflow from and outflow to the subarctic oceans also occur via passages in the Canadian Archipelago. The water masses that enter the Arctic Basin, especially the ones from the Atlantic Ocean, are considerably warmer than those that exit from the Arctic Basin and are considered as an important source of heat flux for the Arctic Ocean (Aagaard and Greisman 1975). The pathways along which the warm water spreads in the Arctic Ocean influence the regional heat flux from the ocean to sea ice and the atmosphere, and thus affect the Arctic climate system. 
In the surface layer, the ocean circulation is forced primarily by surface stress due to wind or ice drift. Modeling studies have shown that the surface circulation varies profoundly in response to changes in the atmosphere and ice motion (e.g., Proshutinsky and Johnson 1997; Maslowski et al. 2000; Hakkinen and Geiger 2000). Below a very shallow Arctic Ocean thermocline layer (about 100-150 $\mathrm{m}$ in depth) the circulation is driven primarily by thermohaline processes, such as lateral inflows and outflows. Oceanic observations in the Arctic Ocean are extremely scarce, so our knowledge of three-dimensional structure of the basinwide circulation remains primitive. Available data nevertheless indicate one prominent feature of a basinwide cyclonic rim current system in the middepth range, shown schematically in Fig. 1 (Rudels et al. 1994; Rudels and Friedrich 2000; Jones et al. 1995). The inflow of the Atlantic Ocean water through Fram Strait and the Barents Sea feeds the cyclonic rim current in the Eurasian Basin. While a portion of the Atlantic water recirculates within the Eurasian Basin, the rest moves across the Lomonosov Ridge into the Makarov Basin, and over the Alpha-Mendeleyev Ridge into the Canada Basin. Subsurface ocean circulations are believed to be cyclonic in both the Makarov and Canada Basins.

Owing to the presence of a very shallow $(<100 \mathrm{~m}$ in depth) halocline layer (Aagaard et al. 1981), the water mass beneath the Arctic halocline is not directly ventilated to the surface mixed layer with exception to localized shelf polynyas in the ice-growth season. Therefore, the vast watermass layer beneath the Arctic halocline and thermocline is probably not forced directly by wind and ice stress. Thermohaline processes become important for circulations in subsurface and deep layers. Figure 1 shows schematically how the inflowing water mass from the Atlantic Ocean circulates and exits the Arctic Ocean. How this circulation pattern is established remains to be explored. If the circulation is a source- and sink-driven one, as described by the classical abyssal ocean circulation theory established by Stommel (1958) and Stommel and Arons (1960a,b), Kelvin and Rossby waves excited by the watermass sources and sinks play a leading role in establishing the steady circulation (Kawase 1987). One would expect the circulation pattern like the one shown in Fig. 1 to be robust and readily simulated by a model with adequate representation of basic dynamics. However, simulating this circulation pattern, even with some of the most sophisticated ocean models, has been more difficult than expected. For instance, an international consortium, the Arctic Ocean Model Intercomparison Project (AOMIP), has recently compared results from 14 different Arctic Ocean models from some of the most prominent Arctic modeling centers (Proshutinsky et al. 2001). All AOMIP models use the same forcing fields but vary in model resolutions. Some models have produced circulations and rim currents similar to the one shown in Fig. 1, but many others have generated flow patterns that go in exactly the opposite direction (A. Proshutinsky and G. Holloway 2004, personal communication). In fact, among 11 model results that are currently posted on the AOMIP Web site, 6 models produced cyclonic circulations and the remaining 5 models generated anticyclonic ones (information available online at http://www.planetwater.ca/research/AOMIP/ index.html). Some opposite results were actually generated by very similar model codes, such as the Geophysical Fluid Dynamics Laboratory Modular Ocean Model. It is quite puzzling why similar models, when driven by the identical forcing field, produce results that are so drastically different. While improving the representation of eddy-topography interaction, that is, the Neptune parameterization, can switch the anticyclonic circulation to the cyclonic one (Holloway 1992; Nazarenko et al. 1998; Polyakov 2001), it remains unexplained why those models, some with eddy-permitting resolutions, generated the opposite results in the first place.

The goal of this paper is not to examine the outputs from a large number of OGCM simulations or to identify specific process that set circulation pattern in each of the AOMIP models; that is clearly beyond the scope of this study. Instead, our objective is to explore the most likely mechanism that can influence fundamentally a source- and sink-driven circulation in a model with Arctic-relevant physical and geometric parameters. In this paper, we settle on the role of potential vorticity (PV) based on what was learned in a midlatitude gyre circulation, to be explained later in section 4. We will show how easily the circulation can be reversed, even with an identical forcing, by making a localized change of PV flux. Two sets of numerical experiments will be conducted. The first one uses a realistic Arctic bathymetry with observed inflow and outflow transports. The second set uses a highly idealized bathymetry to elucidate the essential dynamics without the complication of highly irregular topography. The numerical results will be compared with a theoretical constraint derived by integrating the PV equation over the whole basin.

The paper is organized as follows. The ocean model will be introduced in the next section. Results from two experiments that use a realistic Arctic bathymetry will be presented in section 3. We will explain the results in terms of PV flux in section 4 where an idealized model bathymetry will be used to help elucidate the PV con- 

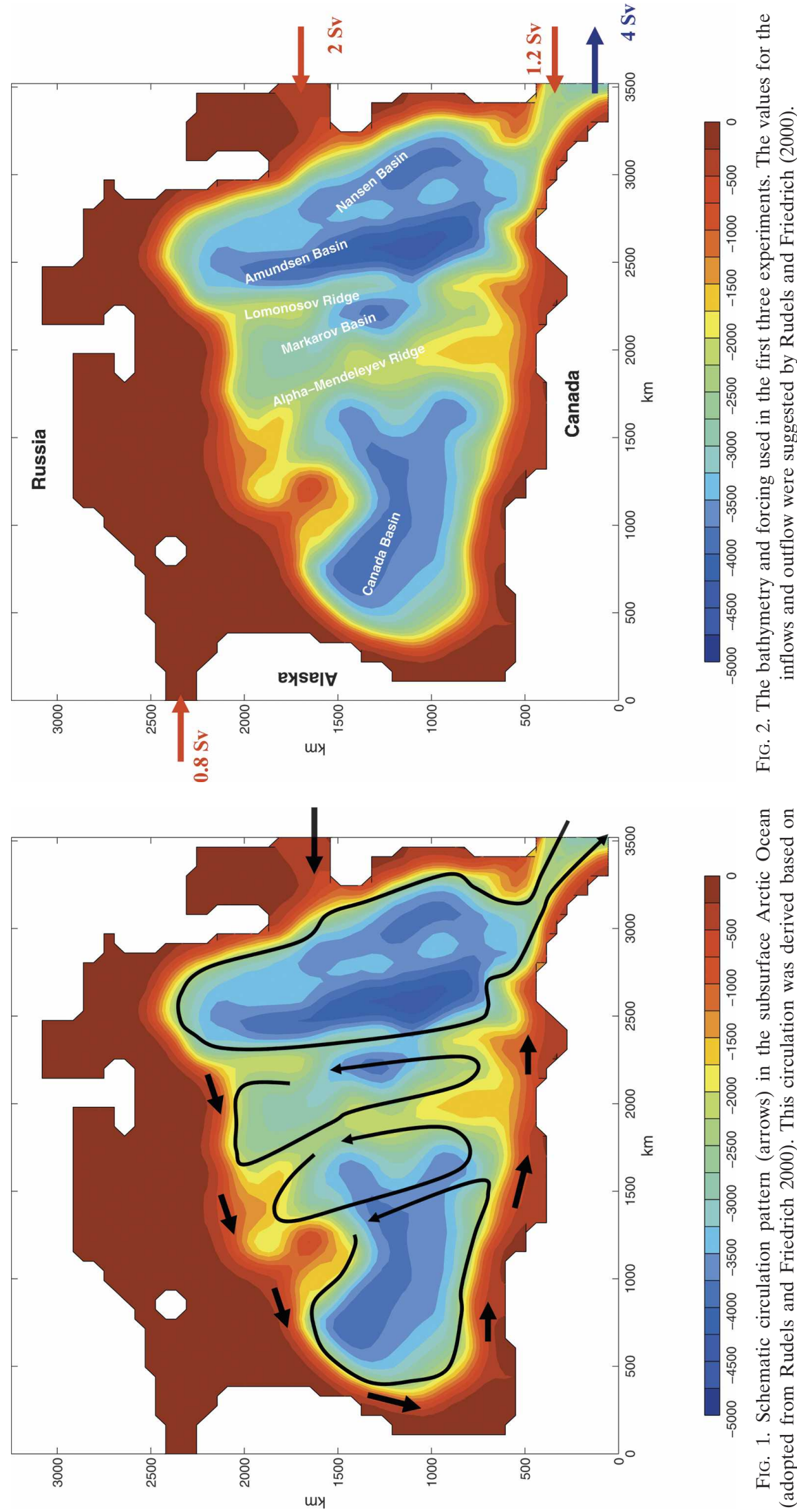

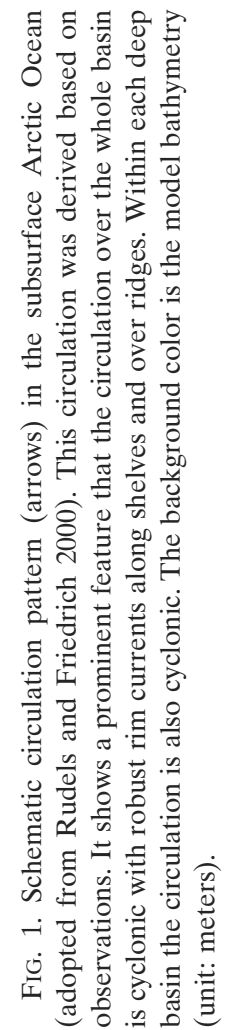


straint in the cleanest possible way. How the PV-integral constraint can be applied to a three-dimensional model will be discussed in section 5 . The paper will finish with a short summary.

\section{Model description}

Our goal is to demonstrate how the Arctic/subarctic flux of the PV affects the circulation, especially the rim current structure, in the Arctic Ocean by using the simplest possible model. Here, we choose a one-layer barotropic ocean model with varying bathymetry. As we will discuss later, both theoretical and numerical results are not model specific and can be applied to any density layer in a three-dimensional model. In the Arctic Ocean, the planetary vorticity $f$ is nearly constant, that is, $\beta=d f / d y \approx 0$, so the relative vorticity $\zeta$ and its gradient may play an important role in the PV dynamics. Therefore, we will use a fully nonlinear model so that advection of the relative vorticity is included. In those experiments that use the realistic Arctic bathymetry, the basin is semienclosed with only three open channels to represent Bering and Fram Straits and the Barents Sea. No-normal-flow and nonslip boundary conditions are applied along the solid boundary. Inflow and/or outflow conditions are specified in open channels in the along-channel component of the velocity field. The transport for each inflow or outflow is specified according to observed values. We are mostly interested in the steady circulation here so that the forcing at the open boundaries is steady. For the cases with realistic Arctic bathymetry, we use a resolution of $55 \mathrm{~km}-$ the same as the one used by the AOMIP consortium (Proshutinsky et al. 2001). The Coriolis parameter $f$ is evaluated at each grid according to its latitudinal position. As pointed out in the introduction, the same model will be applied to a series of numerical runs that use idealized bowl-shape bathymetry. The purpose of this second set of experiments is to elucidate the role of PV flux in shaping the rim current. The resolution for these experiments is $7.5 \mathrm{~km}$. In all experiments, the model is forced only by inflow and outflow. No surface stress is applied. The model is governed by the following equations:

$$
\begin{aligned}
\frac{D u}{D t}-f v+g \frac{\partial h}{\partial x} & =\frac{A_{H}}{H} \nabla \cdot(H \nabla u)+F^{x}, \\
\frac{D v}{D t}+f u+g \frac{\partial h}{\partial y} & =\frac{A_{H}}{H} \nabla \cdot(H \nabla v)+F^{y}, \text { and } \\
\frac{D H}{D t}+H\left(\frac{\partial u}{\partial x}+\frac{\partial v}{\partial y}\right) & =0,
\end{aligned}
$$

where $A_{H}=1000 \mathrm{~m}^{2} \mathrm{~s}^{-1}$ is the horizontal viscosity, $H$ is the layer thickness of the water mass, $h$ is the sea surface height relative to the basin-averaged level, $\mathbf{F}=$ $\left(F^{x}, F^{y}\right)$ is the bottom stress, $g=9.8 \mathrm{~m} \mathrm{~s}^{-2}$ is the gravitational acceleration rate, and $(u, v)$ are velocity components. The Arakawa staggered $\mathrm{C}$ grid is used here. In all experiments, the model is integrated in time from a state of rest. While the spinup process is interesting, we will only address the steady circulation in this paper. We set the model's minimum depth to be $100 \mathrm{~m}$. We have tested cases with minimum depth to $15 \mathrm{~m}$, and the overall solution does not change significantly.

\section{The results from Arctic Ocean experiments}

In this section, results from experiments that use the Arctic bathymetry will be presented. The model, described by (1)-(3), is spun up to a steady state by three inflows- $-8.8 \mathrm{~Sv}\left(\mathrm{~Sv} \equiv 10^{6} \mathrm{~m}^{3} \mathrm{~s}^{-1}\right)$ enters through Bering Strait, 1.2 Sv through the eastern side of Fram Strait, and $2 \mathrm{~Sv}$ through the Barents Sea-and by an outflow of $4 \mathrm{~Sv}$ as the East Greenland Current to the Nordic Seas. Those numbers were based on what was suggested by Rudels and Friedrich (2000). The inflow and outflow are specified in the velocity at those three opening gaps that connect the Arctic Basin to the Bering and Nordic Seas. The model geometry and forcing are shown in Fig. 2. The results shown here are from the end of the 1000th model year, long after it reached the steady state.

The Arctic Ocean bathymetry varies profoundly from several thousands of meters in deep basins to very shallow and broad shelf regions (Fig. 2). So we will present the transport velocity $\mathbf{U}=(H u, H v)$, instead of the velocity $(u, v)$, to better illustrate how the inflowing water masses are distributed. Figure 3 shows that the model circulation is dominantly cyclonic over the whole basin. The Pacific water that enters the Arctic Basin through Bering Strait flows along the Alaskan and Canadian coasts and exits along Greenland through Fram Strait. The Atlantic water flows into the model domain through the eastern side of Fram Strait and via the Barents Sea. Once in the Arctic Basin, it feeds a cyclonic rim current in the Eurasian Basin. The Arctic Mid-Ocean Ridge divides the Eurasian Basin into two smaller basins: the Nansen and Amundsen Basins. There is a weak current above the Arctic Mid-Ocean Ridge directed eastward to the Russian coast. When it reaches the shelf break off the Laptev Sea, it turns clockwise against the much stronger cyclonic rim current and forms a weak and localized anticyclonic gyre within the eastern end of the Nansen Basin. In the southwestern Nansen Basin just to the northeast of 

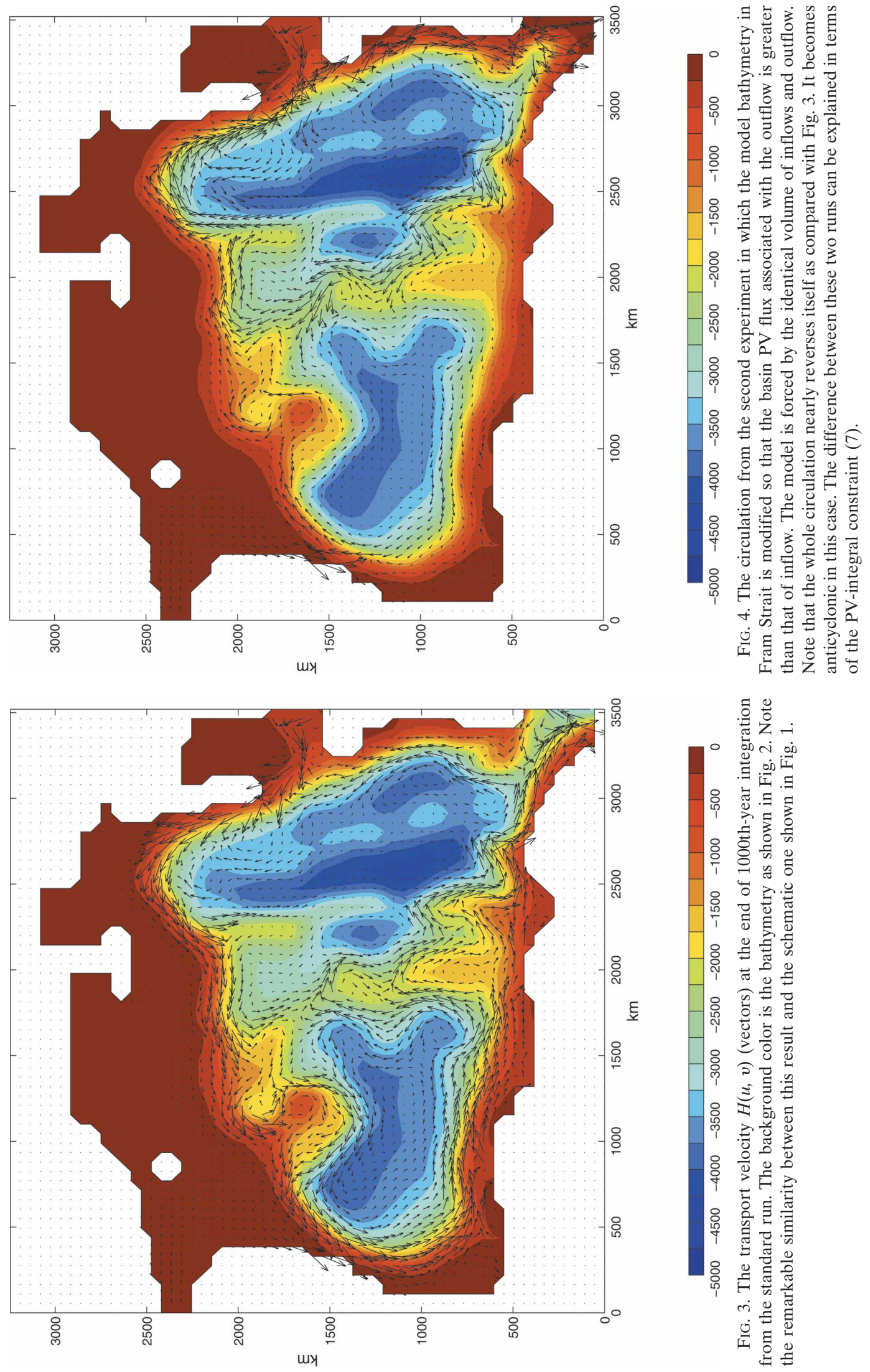
Fram Strait, the basin is deeper and there is a localized cyclonic recirculation there. In the Amundsen Basin between the Arctic Mid-Ocean Ridge and Lomonosov Ridge, there is a weak cyclonic circulation. The circulation in the Makarov Basin located between Lomonosov Ridge and Alpha-Mendeleyev Ridge is also cyclonic, consistent with the one derived from observations shown in Fig. 1. There is a strong flow, following bathymetry, from the Makarov Basin to the Amundsen Basin through a deep passage in the Lomonosov Ridge. Since the circulations in both the Makarov and Amundsen Basins are cyclonic, the currents on either side of the Lomonosov Ridge are opposite to each other. It is interesting to note that there is a strong flow over the Alpha-Mendeleyev Ridge directed from the shelf break off the East Siberian Sea toward the Canadian Archipelago. In the Canadian Basin, there is a very robust cyclonic circulation. Through deeper passages in the Alpha-Mendeleyev Ridge, there are flows between the Canadian and Makarov Basins. To summarize, the basinwide circulation is dominantly cyclonic with robust rim currents along shelves and ridges. Robust cyclonic circulations are evident in deep basins such as in the Canadian, Makarov, and Amundsen Basins. Bathymetry, which sets the PV distribution, strongly influences the pathways. The model, despite its simplicity, captures most of the key features illustrated in Fig. 1.

The circulation shown in Fig. 3 seems to be very robust. The inflows from the subarctic oceans enter the basin, turn cyclonically following isobaths, and exit at Fram Strait. Can this circulation pattern be reversed by the same forcing? Instead of offering a prior explanation of the purpose, here we will show the result of the next experiment, in which a partial dam is built at Fram Strait (cf. Table 1 and Table 2 for the change). The bathymetry is unchanged elsewhere. The model is forced by the identical volume transports at three open channels. Like the standard run shown in Fig. 3, the model was spun up from a state of rest for 1000 years. The transport velocity, shown in Fig. 4, is dramatically different from that in the standard run. The direction of the rim currents along shelves and ridges and of the

TABLE 1. Arctic and subarctic ocean fluxes in the standard run.

\begin{tabular}{lccc}
\hline \hline & $\begin{array}{c}\text { PV flux } \\
\left(\mathrm{m}^{2} \mathrm{~s}^{-2}\right)\end{array}$ & $\begin{array}{c}\text { Volume } \\
\text { flux }(\mathrm{Sv})\end{array}$ & $\begin{array}{c}\text { Sill depth } \\
(\mathrm{m})\end{array}$ \\
\hline Bering Strait inflow & 1.078 & 0.8 & 100 \\
Barents Sea inflow & 0.796 & 2.0 & 369 \\
Fram Strait inflow & 0.109 & 1.2 & 1797 \\
Fram Strait outflow & -0.200 & -4.0 & 2795 \\
Total & 1.7830 & 0.0 & \\
\hline
\end{tabular}

TABLE 2. Arctic and subarctic ocean fluxes in the modified topography run.

\begin{tabular}{lccc}
\hline \hline & $\begin{array}{r}\text { PV flux } \\
\left(\mathrm{m}^{2} \mathrm{~s}^{-2}\right)\end{array}$ & $\begin{array}{c}\text { Volume } \\
\text { flux }(\mathrm{Sv})\end{array}$ & $\begin{array}{c}\text { Sill depth } \\
(\mathrm{m})\end{array}$ \\
\hline Bering Strait inflow & 1.078 & 0.8 & 100 \\
Barents Sea inflow & 0.796 & 2.0 & 369 \\
Fram Strait inflow & 1.058 & 1.2 & 162 \\
Fram Strait outflow & 4.544 & -4.0 & 128 \\
Total & -1.612 & 0.0 & \\
\hline
\end{tabular}

circulations in all deep basins is actually reversed. In fact, the entire circulation patterns are nearly opposite between these two model runs. How can a localized change in the sill depth at Fram Strait have such a powerful influence on the basin-scale circulation? What does this imply to a three-dimensional flow? To explore this, we proceed to the discussion of PV-integral constraint in the next section.

\section{A constraint of the potential vorticity integral}

A circulation must satisfy many types of integral constraints, such as mass, energy, and so on. However, in this study, we focus on the role of PV because it is, in our opinion, most relevant to the model's selection of circulation direction, based on what has been learned in gyre circulations in midlatitude oceans. In the subtropical gyre in either the northern Pacific or Atlantic Ocean, for instance, the negative curl of wind stress forces an equatorward Sverdrup flow in the ocean interior. But the circulation could still be either cyclonic or anticyclonic. If the circulation were closed by an eastern boundary, it would be a cyclonic gyre, and vice versa for the western boundary closure. It is the requirement to dissipate the negative PV flux associated with the wind stress curl that demands that the gyre circulation be anticyclonic with an intensified western boundary layer current (see Pedlosky 1979, 1996 for reviews).

For a layer of water mass in a semienclosed basin, the integral of the PV budget over the whole basin yields a balance between the boundary PV dissipation and the net lateral PV inflow (Yang and Price 2000). Using an idealized and linear model, Yang and Price (2000) studied the PV balance in the Stommel-Arons (1960) abyssal circulation. It was found that the circulation pattern, especially the boundary current, is very sensitive to how the water mass is introduced in the basin. A diapycnal mass flux does not change the PV integral and, thus, the net dissipation must be zero. A lateral inflow, however, brings $\mathrm{PV}$ into the basin and thus requires it to be dissipated by boundary currents. The magnitude of such a PV flux depends mainly on the planetary PV $f / H$ and the mass transport at the inflow. 


\section{a. The theoretical form}

Following Yang and Price (2000), we derive here the area integral of the PV equation from (1)-(3) in the form of line integral along the side boundary $C$ :

$$
\oint_{C}(\mathbf{U} \cdot \mathbf{n})\left(\frac{f+\zeta}{H}\right) d s=\iint_{A} D_{p} d x d y+\oint_{C}(\mathbf{F} \cdot \mathbf{l}) d s
$$

where $\mathbf{n}$ is the unit vector perpendicular to the lateral boundary $C, H$ is the layer thickness, $\mathbf{U}=H(u, v)$ is the transport velocity vector, $\zeta=v_{x}-u_{y}$ is the relative vorticity, $\mathbf{F}$ is the surface stress, which is set to be zero in this model, and $D_{p}$ is the PV dissipation term, which has the following form:

$$
D_{P}(x, y)=\frac{\partial}{\partial x}\left[\frac{A_{H}}{H} \nabla \cdot(H \nabla v)\right]-\frac{\partial}{\partial y}\left[\frac{A_{H}}{H} \nabla \cdot(H \nabla u)\right] \text {. }
$$

If the inflow and outflow are mainly along channels, that is, the cross-channel velocity is smaller, the transport of relative $\mathrm{PV}$, that is, $\zeta / H$, integrated across the channel will vanish in a model using a no-slip boundary condition [see Yang and Price (2000) for the derivation]. In practice, the relative vorticity $\zeta$ is usually much smaller than $f$, so, even if the flow has a strong crosschannel component, the transport of PV would be dominated by the planetary one. In either case, the PV integral (4) can be simplified to

$$
\sum_{i=1}^{N} \frac{Q_{i} f_{i}}{H_{i}}=\iint_{A} D_{p}(x, y) d x d y+\oint_{C}(\mathbf{F} \cdot \mathbf{l}) d s,
$$

where $Q_{i}$ is the volume transport of the water mass into the basin at $i$ th opening and $f_{i} / H_{i}$ is the $\mathrm{PV}$ at that location. There is no surface or bottom stress applied in our model (1)-(3), so the last term in (6) is zero. The Arctic Basin has broad shelves, so the spatial scale of topographic variation is broad along the side boundary. In that case, the complicated form of dissipation can be dramatically simplified to

$$
\iint_{A} D_{p}(x, y) d x d y \approx A_{H} \oint_{C} \nabla \zeta \cdot \mathbf{n} d s
$$

If we also applied a Rayleigh friction at the bottom, the dissipation would become

$$
\iint_{A} D_{p}(x, y) d x d y \approx A_{H} \oint_{C} \nabla \zeta \cdot \mathbf{n} d s-\lambda \oint_{C}(\mathbf{u} \cdot \mathbf{l}) d s,
$$

where $\lambda$ is the Rayleigh friction coefficient. We have run experiments that used either both frictions or just one of them. The sense of the control that the PV integral exerts on the circulation direction is not changed, the same as what was found by Yang and Price (2000) in their abyssal ocean circulation. For the results presented here, the model used only lateral mixing, so the balance of the PV integral is between the PV flux associated with the lateral inflow/outflow, that is, the lefthand-side term in (6), and the dissipation represented by the first term on the right-hand side; that is,

$$
\sum_{i=1}^{N} \frac{Q_{i} f_{i}}{H_{i}} \approx A_{H} \oint_{C} \nabla \zeta \cdot \mathbf{n} d s .
$$

In the Arctic Basin, $f$ is nearly constant, so (7a) becomes

$$
\begin{aligned}
& f\left(\frac{Q_{\text {Bering }}}{H_{\text {Bering }}}+\frac{Q_{\text {Barents }}}{H_{\text {Bering }}}+\frac{Q_{\text {Fram }}^{\text {in }}}{H_{\text {Fram }}^{\text {in }}}-\frac{Q_{\text {Fram }}^{\text {out }}}{H_{\text {Fram }}^{\text {out }}}\right) \\
& \approx A_{H} \oint_{C} \nabla \zeta \cdot \mathbf{n} d s,
\end{aligned}
$$

where $Q$ and $H$ are the volume transport and layer thickness at each opening.

\section{b. PV-integral constraint in the model simulations}

The sense of circulation, as shown in (7), is strongly influenced by the net PV advection into the basin. In the first experiment, shown in Fig. 3, the water mass through Bering Strait $\left(Q_{\text {Bering }}=0.8 \mathrm{~Sv}\right)$ and Barents Sea $\left(Q_{\text {Barents }}=2 \mathrm{~Sv}\right)$ carries high PV because of the shallowness at the inflows. The third inflow through Fram Strait $\left(Q_{\text {Fram }}^{\text {in }}=1.2 \mathrm{~Sv}\right)$ has a lower PV because of the deeper passage. The only outflow in the model occurs through Fram Strait $\left(Q_{\text {Fram }}^{\text {out }}=4 \mathrm{~Sv}\right)$ where the water mass has a low PV value. The PV flux budget in this experiment is summarized in Table 1. The total PV flux is so clearly dominated by the flux through Bering Strait where the channel is shallow (the real depth is even shallower than $100-\mathrm{m}$ minimum depth set in the model). Although the net inflow and outflow are in exact balance in terms of volume transport (4 Sv), there is a significant gap between PV flux into and out of the basin. Namely, the Arctic Basin receives a net amount of positive PV $\left(1.783 \mathrm{~m}^{2} \mathrm{~s}^{-2}\right)$ through the watermass exchanges with the subarctic Ocean. The frictional processes must generate the same amount of PV so that the budget can be balanced. It is known that the diffusion of the negative PV from a frictional boundary layer occurs when the flow is cyclonic. The cyclonic circulation shown in Fig. 3 agrees with the flow pattern expected from this PV consideration. To support that, we 
have plotted the distribution of the relative vorticity $\zeta$ in Fig. 5. There is a layer of negative $\zeta$ along the coast, except over a short distance along the Russian coast in the Chukchi Sea in the downstream of the Bering Strait inflow. There is a positive layer of $\zeta$ immediate offshore to the boundary layer. This structure results in a diffusion of negative PV into the basin. The basinwide integration of the dissipation $D_{p}(x, y)$, defined by (5), yields $-1.675 \mathrm{~m}^{2} \mathrm{~s}^{-2}$, which compares reasonably well to the theoretically expected value of $1.783 \mathrm{~m}^{2} \mathrm{~s}^{-2}$.

The change of bathymetry in the second experiment affects the PV budget as shown in Table 2, which summarizes how the change of bathymetry at Fram Strait affects the PV flux into the basin. The PV fluxes through Bering Strait and the Barents Sea remain the same. The PV fluxes both into and out of the Arctic Basin through Fram Strait have increased in response to the bathymetry change. But the total PV flux into the Basin becomes negative $\left(-1.612 \mathrm{~m}^{2} \mathrm{~s}^{-2}\right)$, as compared with a positive one in the standard run. The distribution of $\zeta$ (Fig. 6) becomes very different. While the diffusion of negative PV has weakened significantly along the Canadian and Alaskan coasts, there is very strong diffusion of positive PV into the Eurasian Basin. Overall, the whole basin receives a net positive PV diffusion of $1.459 \mathrm{~m}^{2} \mathrm{~s}^{-2}$, about $91 \%$ of the theoretically expected value $\left(1.612 \mathrm{~m}^{2} \mathrm{~s}^{-2}\right)$.

In the previous two experiments, it was shown that the model circulation can either be cyclonic or anticyclonic depending on the net budget of PV inflow/outflow. One may wonder what would happen if the net $\mathrm{PV}$ advection into the basin is zero. Obviously, the net PV dissipation (or production due to friction) must be zero, as mandated by (7). But the water mass must flow from its sources (inflows) to the sink (outflow), and its pathway is likely along the boundary, which would certainly result in PV diffusion into the basin. How can the circulation reconcile this? To find out, we decided to conduct another experiment. The topography at Fram Strait is modified such that the PV outflow cancels exactly the net PV inflow from Bering Strait, the Barents Sea, and Fram Strait; that is, the left-hand side of (7) is zero. The circulation, shown in Fig. 7, is anticyclonic in the Eurasian Basin but cyclonic in the Canadian Basin. So the friction produces an amount of positive PV in the Eurasian Basin and exactly the same amount of negative PV in the Canadian Basin to satisfy the basinintegral constraint.

\section{c. An idealized model}

To explore and demonstrate the theoretical constraint (7) in the simplest possible way without the com- plication of realistic topography in the previous three experiments, we will use an idealized basin that has only two opening channels, one for the inflow and the other for outflow so that (7) can be simplified to

$$
Q f\left(\frac{1}{H_{\mathrm{in}}}-\frac{1}{H_{\mathrm{out}}}\right)=\iint_{A} D_{p}(x, y) d x d y,
$$

where $H_{\text {in }}=D_{\text {in }}+\eta_{\text {in }}$ and $H_{\text {out }}=D_{\text {out }}+\eta_{\text {out }}$ are watermass thickness at the inflow and outflow, respectively. Since the sea surface height variation $\eta$ is much smaller, the main factor that decides the mean thickness $D(x, y)$ is the topographic variation. If the basin has a flat bottom or its topographic variation is small, the integral of (8) can be approximated by

$$
Q f\left(\frac{1}{H_{\mathrm{in}}}-\frac{1}{H_{\mathrm{out}}}\right)=A_{H} \oint_{C} \nabla \zeta \cdot \mathbf{n} d s .
$$

In the following experiments we will use bowl-shape model bathymetries in our model. The model domain extends from -1500 to $1500 \mathrm{~km}$ in both $x$ and $y$ direction. The model resolution is $\Delta x=\Delta y=7.5 \mathrm{~km}$. A $\beta$ plane is used on which $f$ is specified as $f=f_{0}+$ $\left(r_{0}-r\right) \beta_{0}$, where $\beta_{0}=2 \Omega \cos 80^{\circ} / R, r=\sqrt{x^{2}+y^{2}}$, and $r_{0}=10^{3} \mathrm{~km}$. Basically, the planetary vorticity $f$ is maximum at the center, just like at the North Pole. An inflow of $1 \mathrm{~Sv}$ is specified at $y=1500 \mathrm{~km}$ and an outflow of the same amount is placed at $y=-1500 \mathrm{~km}$. Both inflow and outflow are specified as zonally uniform currents between $x=-90 \mathrm{~km}$ and $x=90 \mathrm{~km}$. Except for these two open channels, the lateral boundary is a solid wall along which no-normal-flow and nonslip boundary conditions are applied. In the first idealized-basin experiment, we use the bathymetry specified by

$$
\begin{aligned}
D(x, y) & =1500 e^{-\left(x^{2}+y^{2}\right) / 1500^{2}} \text { for } \\
r & =\sqrt{x^{2}+y^{2}} \leq 1500 \mathrm{~km} \quad \text { and } \\
D(x, y) & =0 \quad \text { for } \quad r=\sqrt{x^{2}+y^{2}}>1500 \mathrm{~km},
\end{aligned}
$$

where $D(x, y)$ is the seafloor depth. Using this bathymetry, the model (1)-(3) is run to a steady state. The result at the 1000th year shows that the flow from the source to the sink is split evenly into two branches of southern boundary current, a cyclonic current in the Western Hemisphere and an anticyclonic one in the Eastern Hemisphere (Fig. 8). They merge at the exit at $x=0$ and $y=-1500 \mathrm{~km}$ to feed the outflow. The circulation in the interior away from the boundary is 

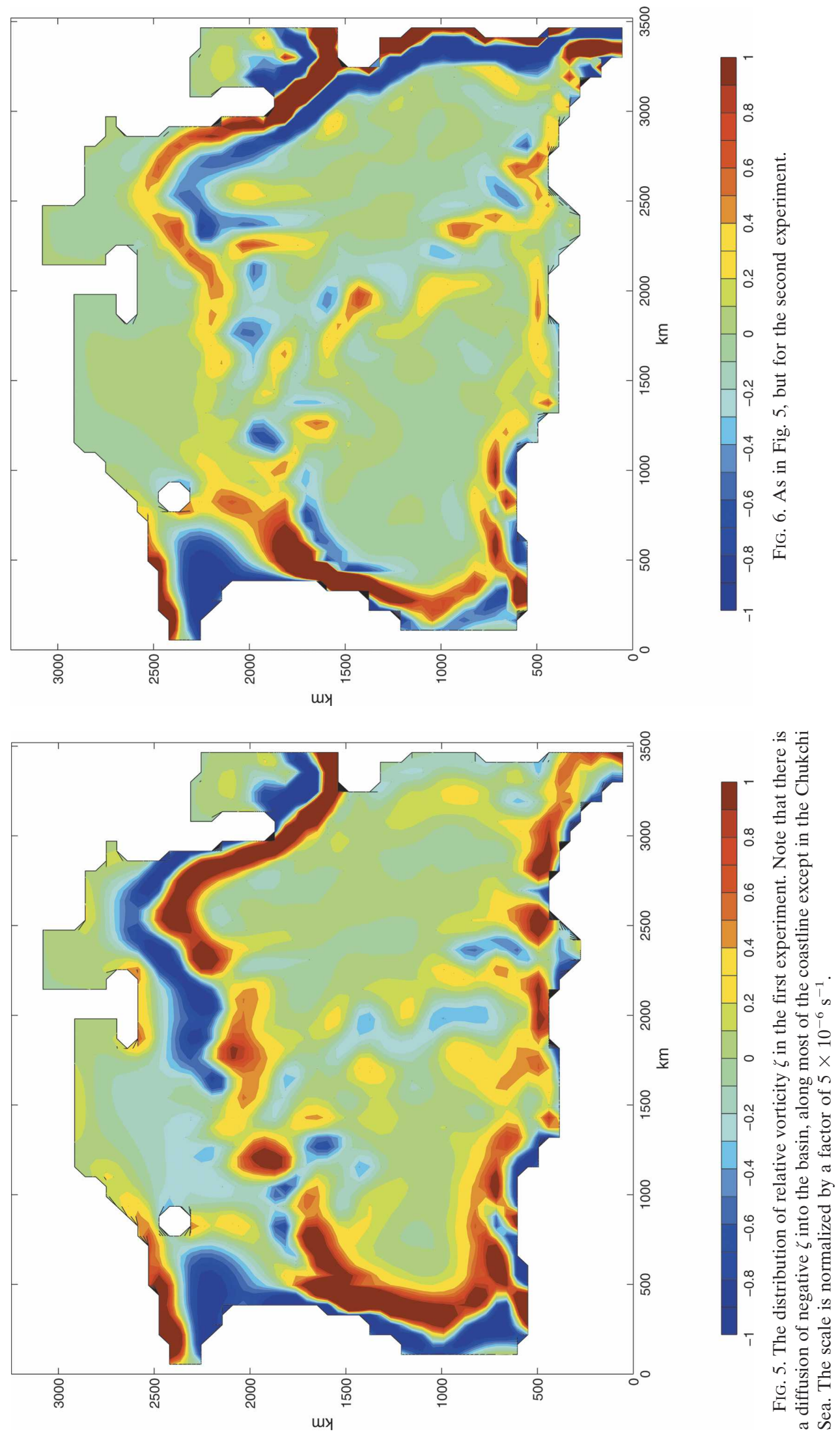


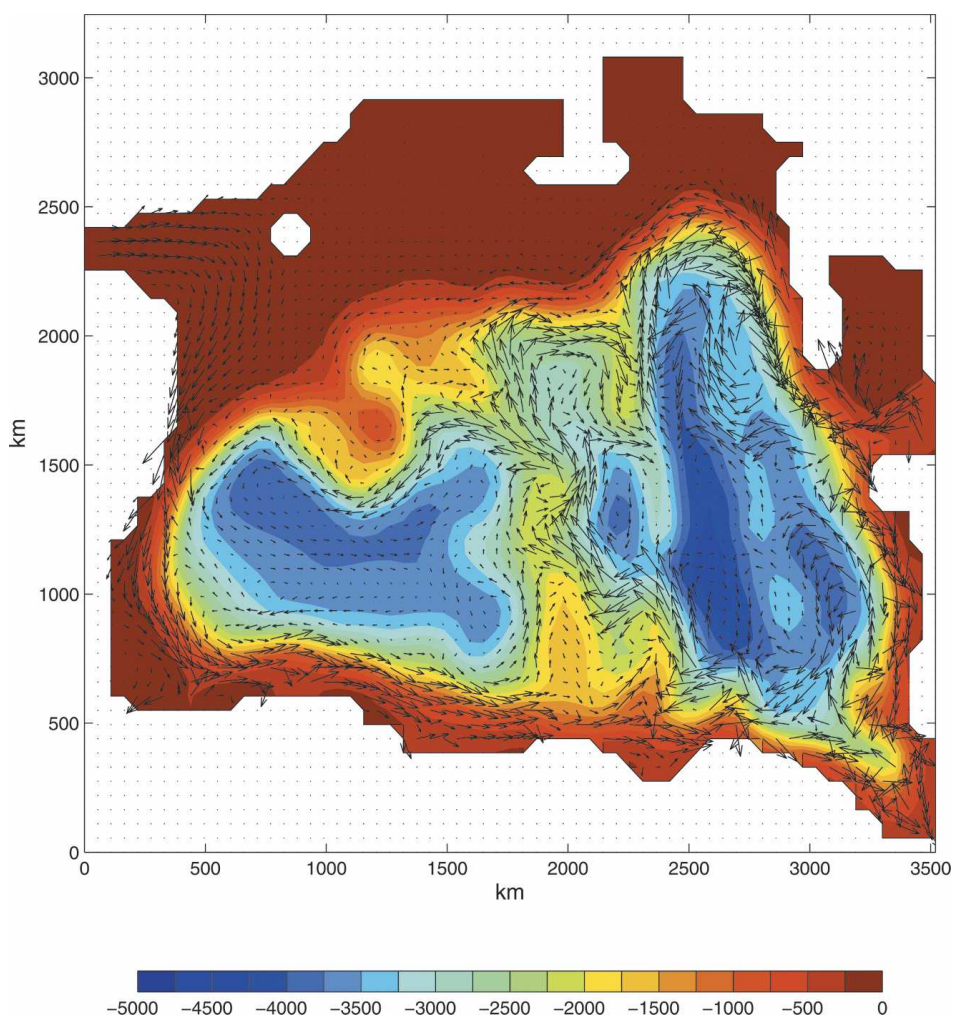

FIG. 7. The circulation from the third experiment in which the model bathymetry in Fram Strait is modified so that the basin PV flux associated with the outflow cancels exactly that from inflow. The PV constraint (7) requires that the net PV dissipation be zero. Note that the circulation is anticyclonic in the Eurasian Basin but is cyclonic in the Canadian Basin.

weak. It is interesting to note that there are countercurrents immediately offshore to the southern boundary currents, especially near the inflow and outflow. For instance, an offshore current flows anticyclonically along isobaths in the Western Hemisphere against the dominant cyclonic boundary current. The countercurrent becomes stronger near the inflow between $y=500$ $\mathrm{km}$ and $y=1500 \mathrm{~km}$, and $x=-1000 \mathrm{~km}$ and $x=0$. The countercurrent continues anticyclonically into the Eastern Hemisphere where it joins the boundary current that flows in the same direction. An opposite countercurrent is also clearly shown in the Eastern Hemisphere near the outflow at $y=-1500 \mathrm{~km}$. It is not very clear why these countercurrents exit, but their existence appears to enhance the PV dissipation at the inflow and outflow that are essential to the selection of the watermass pathways.

The distribution of the relative vorticity $\zeta$ is shown in Fig. 9. In the Western Hemisphere, the relative vorticity is negative in a thin layer along the boundary. It becomes positive just outside this boundary PV layer. This structure leads to a diffusion of negative PV into the basin. It is interesting to note that the flux is enhanced in the area where the anticyclonic countercurrent is strong (in the immediate downstream to the inflow), and the vorticity gradient $\nabla \zeta \cdot \mathbf{n}$ is large. Almost the same pattern, but with an opposite sign, can be found for the relative vorticity $\zeta$ in the Eastern Hemisphere. The flux of PV along the boundary becomes clearer in Fig. 10, which shows the dissipation term as defined by (5). Because the PV dissipations in both hemispheres are nearly opposite to each other, the net integral over the whole basin vanishes. This satisfies the integral constraint (7) since there is no net advection of PV into the basin [i.e., the left-hand side of (7) is zero].

To demonstrate the integral constraint, we modify the bathymetry in the next experiment by tilting the basin slightly in the $y$ direction, that is,

$$
D(x, y)=1500 \times e^{-\left(x^{2}+y^{2}\right) / 1500^{2}}-\frac{y}{15 \mathrm{~km}} .
$$

Because of the second term on the right-hand side of (11), the sill depth at the outflow $(y=-1500 \mathrm{~km})$ is 200 

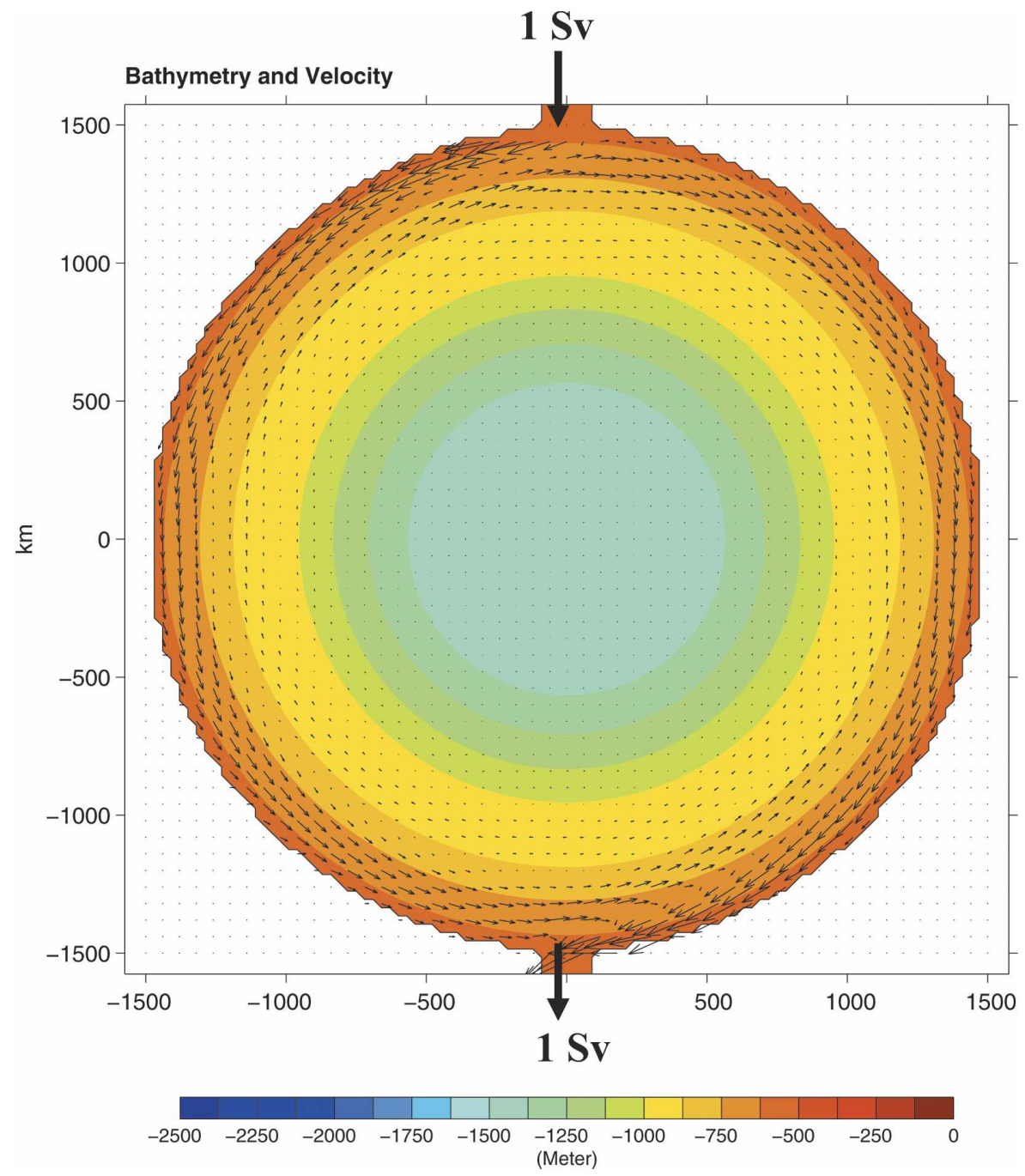

FIG. 8. The circulation in the first idealized bathymetry run. In this case, the inflow and outflow carry the same amount of PV, so the basin integral of PV dissipation is zero. Note that the rim current splits into two branches, a cyclonic one in the Western Hemisphere and an anticyclonic one in the east.

$\mathrm{m}$ deeper than that at the inflow $(y=1500 \mathrm{~km})$. The advective PV flux is no longer in balance now. For the same amount of 1-Sv volume flux, the inflow carries a greater amount of PV than outflow. So, the integral constraint requires friction to generate the negative PV. The strong boundary current, shown in Fig. 11, is dominantly cyclonic and confined in the Western Hemisphere $(x<0)$. The much weaker countercurrent is still visible in areas just offshore to the boundary layer. The distribution of relative vorticity $\zeta$ (Fig. 12) shows two layers of concentrated PV along the boundary in the Western Hemisphere. A very thin layer of negative $\zeta$ is sandwiched between the boundary and an offshore layer of positive $\zeta$. Consequently, the vorticity diffusion into the basin, or the dissipation as defined by (7), is negative and intensified along that portion of boundary (Fig. 13). In this experiment, the PV flux is $0.4 \mathrm{~m}^{2} \mathrm{~s}^{-2}$ for the inflow and $-0.26 \mathrm{~m}^{2} \mathrm{~s}^{-2}$ for the outflow, so the basin receives an amount of $0.14 \mathrm{~m}^{2} \mathrm{~s}^{-2} \mathrm{PV}$. The integration of the dissipation term $D_{p}(x, y)$, as defined by (5), over the whole basin yields $-0.1407 \mathrm{~m}^{2} \mathrm{~s}^{-2}$. So, the model satisfies the theoretical constraint (7) reasonably well.

In the third idealized experiment, we reverse the PV flux by modifying the bathymetry to

$$
D(x, y)=1500 \times e^{-\left(x^{2}+y^{2}\right) / 1500^{2}}+\frac{y}{15 \mathrm{~km}} .
$$

The sill depth at inflow, $y=1500 \mathrm{~km}$, is $200 \mathrm{~m}$ deeper than that at outflow. The model is still forced by the 

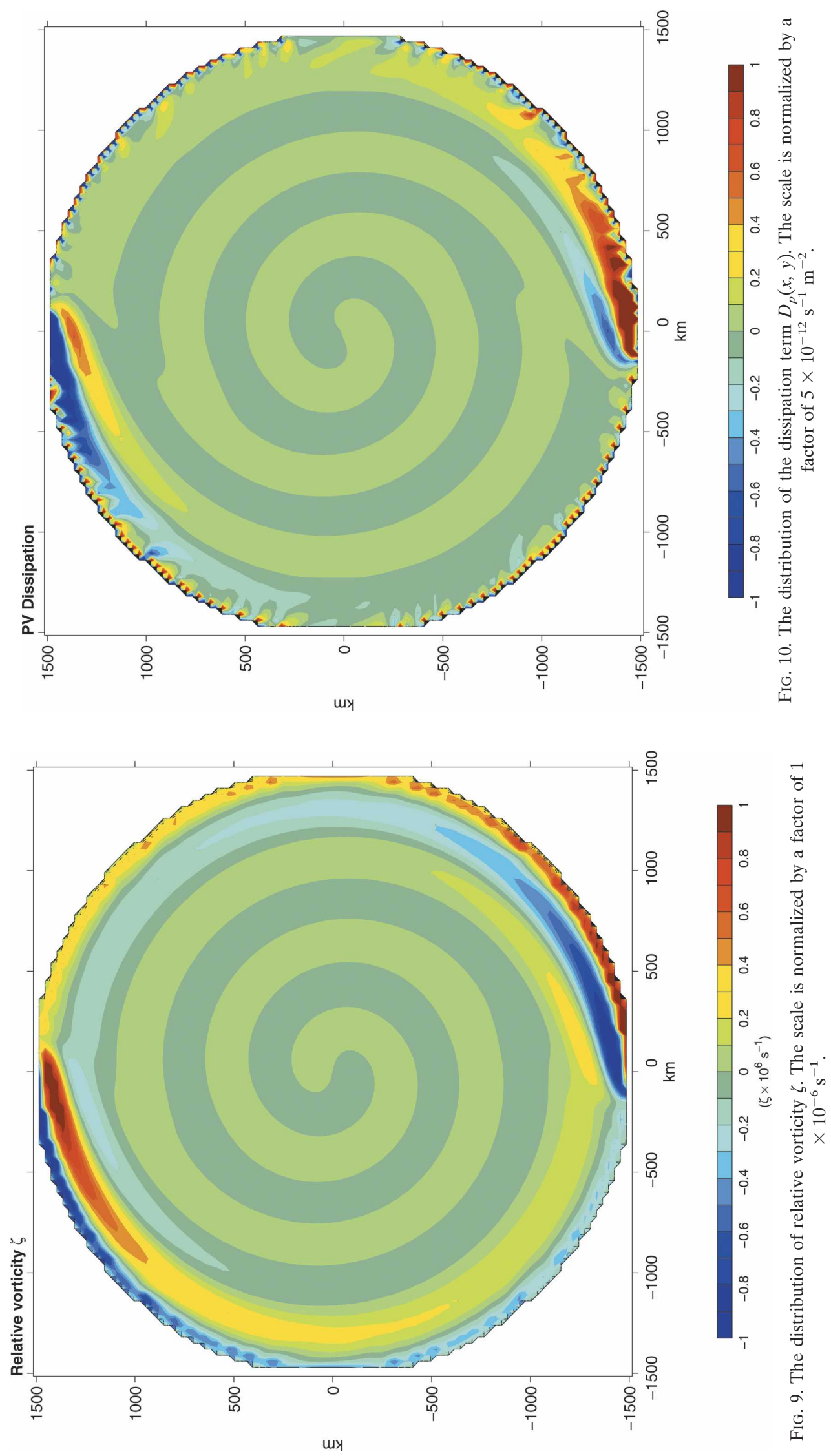

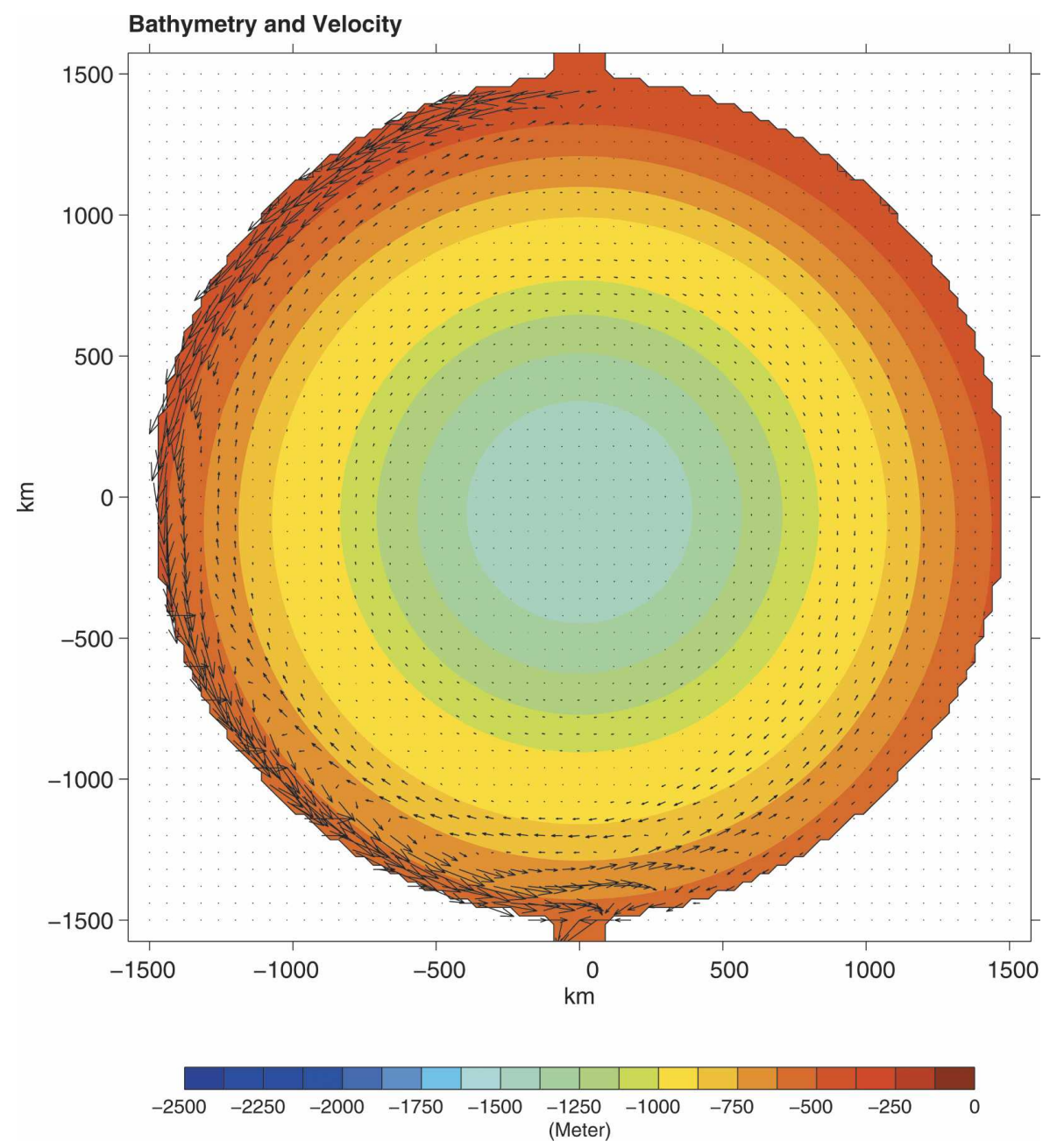

FIG. 11. As in Fig. 5 except that the bathymetry is modified, as described by (11), so that the inflow carries more PV than the outflow. Note that the circulation is dominantly cyclonic.

same inflow and outflow of $1 \mathrm{~Sv}$. The PV flux due to the inflow and outflow is exactly reversed. The friction must produce $0.14 \mathrm{~m}^{2} \mathrm{~s}^{-1}$ of $\mathrm{PV}$ to fill the deficit due to imbalance in the inflow and outflow. Figure 14 shows an anticyclonic circulation that is confined in the Eastern Hemisphere $(x>0)$. Both the relative vorticity $\zeta$ (Fig. 15) and PV dissipation $D_{p}(x, y)$ (Fig. 16) become opposite mirror images to that in the previous experiment. Integrating the dissipation term $D_{p}$ over the whole basin shows that the friction in the model produces $0.1405 \mathrm{~m}^{2} \mathrm{~s}^{-2}$ of PV, satisfying (7) slightly better than in the previous experiment. The results shown in these three experiments with idealized basin bathymetries demonstrate a powerful control of the PV flux on the basinwide circulation. A small and localized change can flip the circulation over the whole basin. Although the change of circulation in each experiment is very consistent with the integral constraint (7), one must wonder why the change of circulation and dissipation have to occur over the basin scale instead of satisfying the integral constraint (7) by intensified dissipations locally near the watermass source and sink. Figures 11 and 14 seem to indicate that the spatial scale of the model response is related to where the inflow and outflow are located. If the outflow is located at a short distance in the downstream of the inflow, the intensified dissipation may occur only in a small area. In such a scenario, recirculations near the boundary often develop to enhance the dissipation in the boundary layer, as shown in coarse-resolution models in a midlatitude ocean (e.g., Yang 2003).

In the previous three experiments that used idealized bathymetry, the PV contours, which are almost identical to the isobaths in the Arctic where $f$ is nearly constant, always connect smoothly between the inflow and the outflow regions along the boundary. What would 

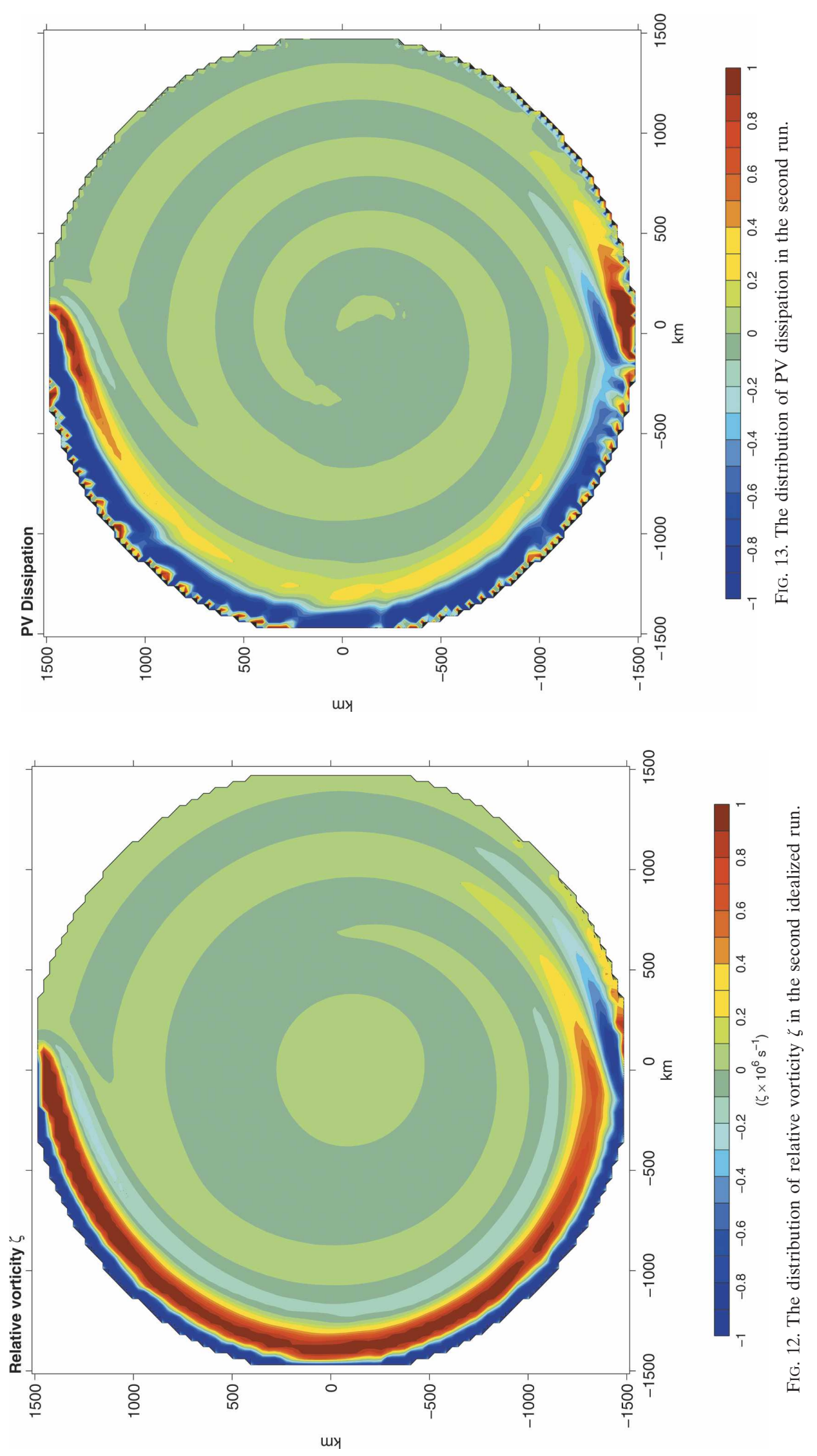

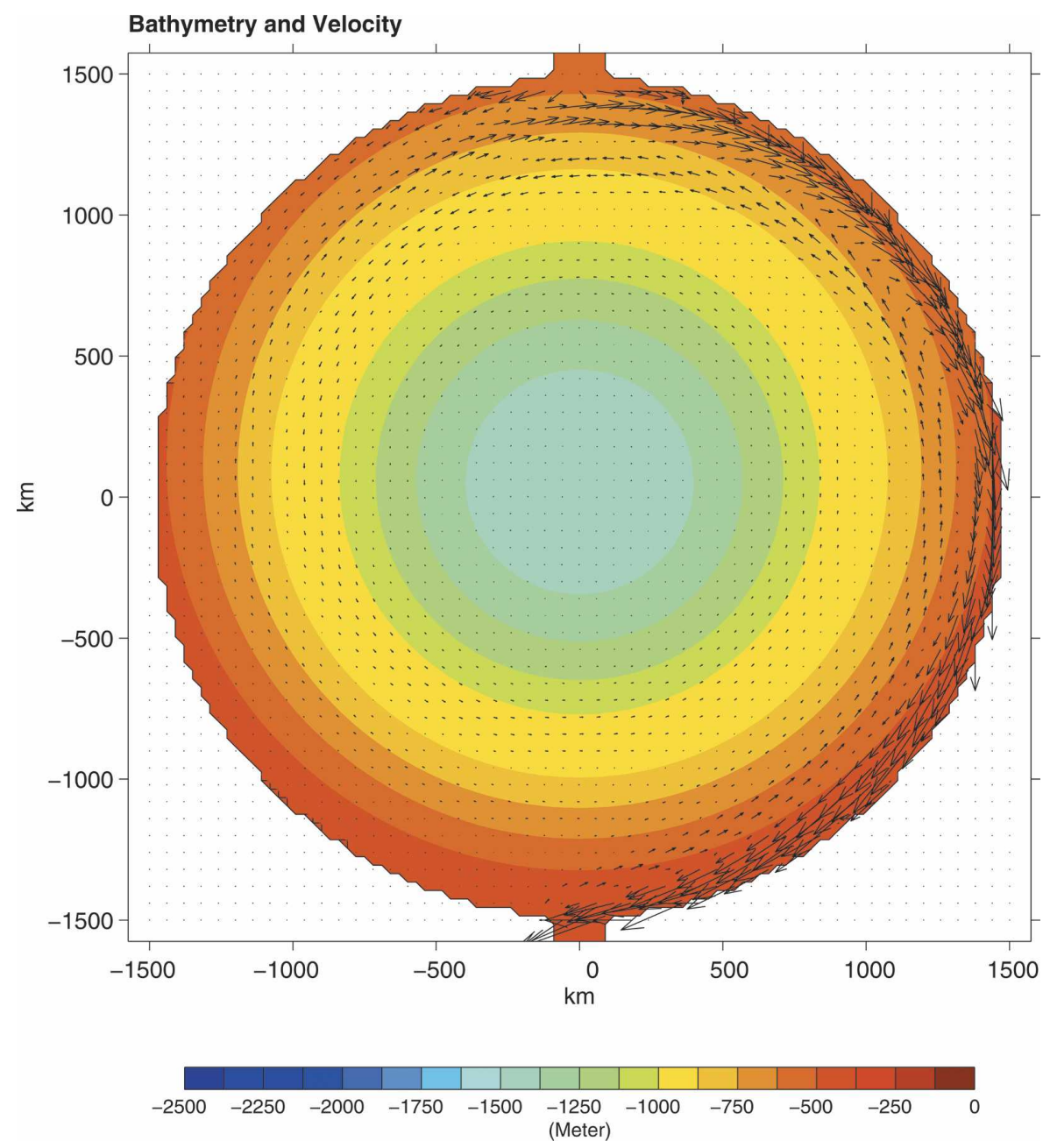

FIG. 14. As in Fig. 5 except the inflow carries less PV than outflow because of the change of bathymetry as shown in (12). The circulation now becomes anticyclonic.

happen if the flow pathways in the previous experiments were disrupted by abrupt changes of bathymetry, such as ridges and trenches that are abundant in the Arctic Basin (Fig. 1)? To explore this, we decided to run two more experiments by disrupting the PV contours in the experiments shown in Figs. 11 and 14. Specifically, a trench is placed between the model's North Pole at $(x, y)=(0,0)$ and the side boundary $(x, y)=$ $(1500 \mathrm{~km}, 0)$. Both the cyclonic (Fig. 11) and anticyclonic (Fig. 14) cases will be revisited with this new topographic feature. It must be stressed here that adding the trench does not affect the PV integral (7) as long as the sill depths of inflow and outflow remain unchanged. In the case of cyclonic circulation, the flow is little affected by the presence of trench since the watermass pathway is located on the other side of the basin (Fig. 17). The distributions $\zeta$ and $D_{p}(x, y)$ are virtually identical to those in the experiment without trench (Figs. 12 and 13) and therefore are not shown here. What will happen to the anticyclonic case in which the trench would be blocking the watermass pathway from the inflow to outflow? The circulation is indeed disrupted by the trench (Fig. 18). Instead of going anticyclonically in the Eastern Hemisphere, as in the original experiment (Fig. 14), the inflow enters the basin and turns cyclonically. It continues its cyclonic pathway in the Western Hemisphere, passes the outflow at $y=-1500 \mathrm{~km}$, and reaches the trench. It then makes a $\mathrm{U}$ turn and forms an anticyclonic boundary current that feeds into the outflow. It is interesting to note that the cyclonic current flows slightly offshore from the source to where the trench is located. The current has also broadened along this pathway. Consequently, the relative vorticity $\zeta$ and its gradient perpendicular to the boundary are relatively small (Fig. 19). Its contribution to the PV dissipation is smaller too, even though its 

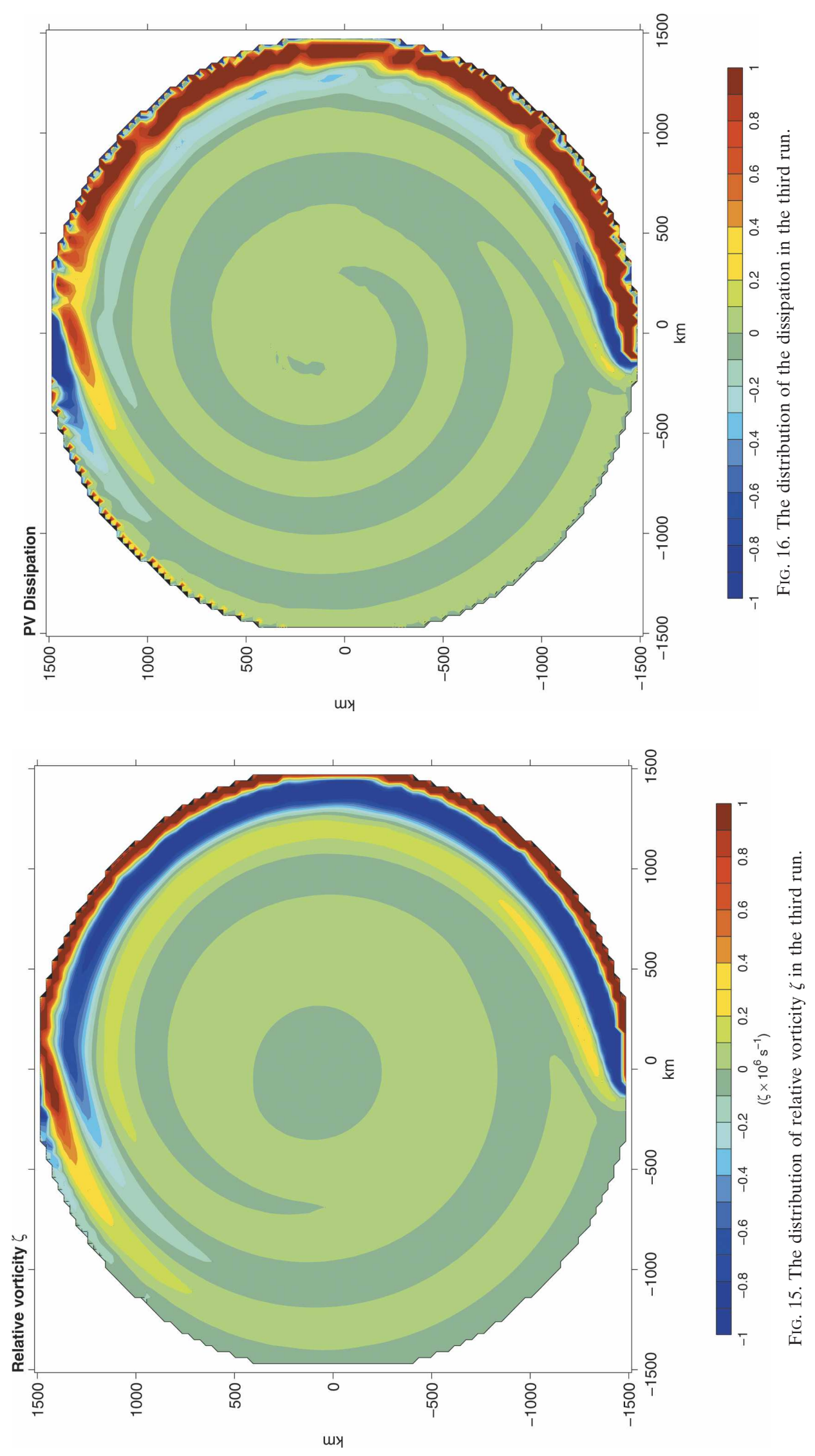


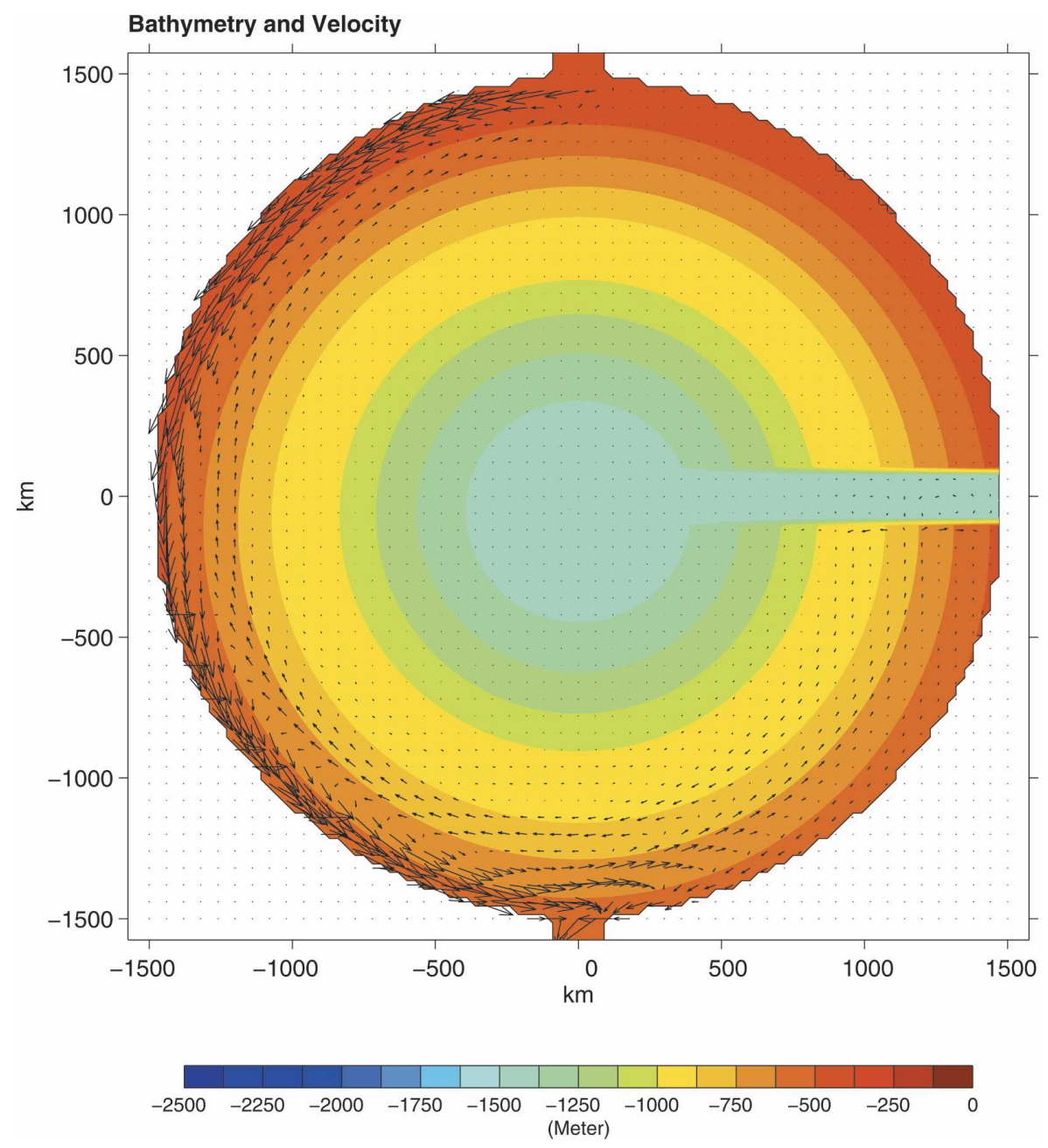

FIG. 17. As in Fig. 8 except with a trench.

pathway extends to two-thirds of the basin's boundary (Fig. 20). In contrast, the anticyclonic current, even though running a short distance, rubs the boundary hard (Fig. 18) and generates a strong gradient of $\zeta$ and thus contributes overwhelmingly to the total dissipation (Figs. 19 and 20). The integration of the total dissipation is $0.134 \mathrm{~m}^{2} \mathrm{~s}^{-2}$, as compared with the theoretically expected value of $0.14 \mathrm{~m}^{2} \mathrm{~s}^{-2}$. We would like to point out that the discussion has been cast for the steady state of each experiment. The spinup process involves the propagation of topographic Rossby waves. In each case, the trench has a profound impact on the spinup process even in the case in which the pathway in the steady solution was little affected by the trench (Fig. 17 as compared with Fig. 11). We have done several additional experiments with abrupt changes of topography, including adding ridges, a trench all the way across the basin, etc. In all those experiments, the PV integral (7) is shown to exert a strong control on the sense of circulation direction. In each case, the integral (7) is satisfied well.

\section{Summary and discussion}

In this paper, we have applied the PV-integral constraint (Yang and Price 2000) to the Arctic Ocean. It was shown that the source- and sink-driven circulation is affected profoundly by the net PV budget associated with the inflow and outflow from the subarctic ocean. If there is a net positive PV advection into the Arctic, the circulation tends to be cyclonic and vice versa for a negative one. The numerical results for all experiments satisfy the theoretic constraint (7) reasonably well. We also show that an abrupt variation of bathymetry that disrupts the PV contours can change the watermass pathways profoundly. But the PV-integral constraint is always satisfied. 


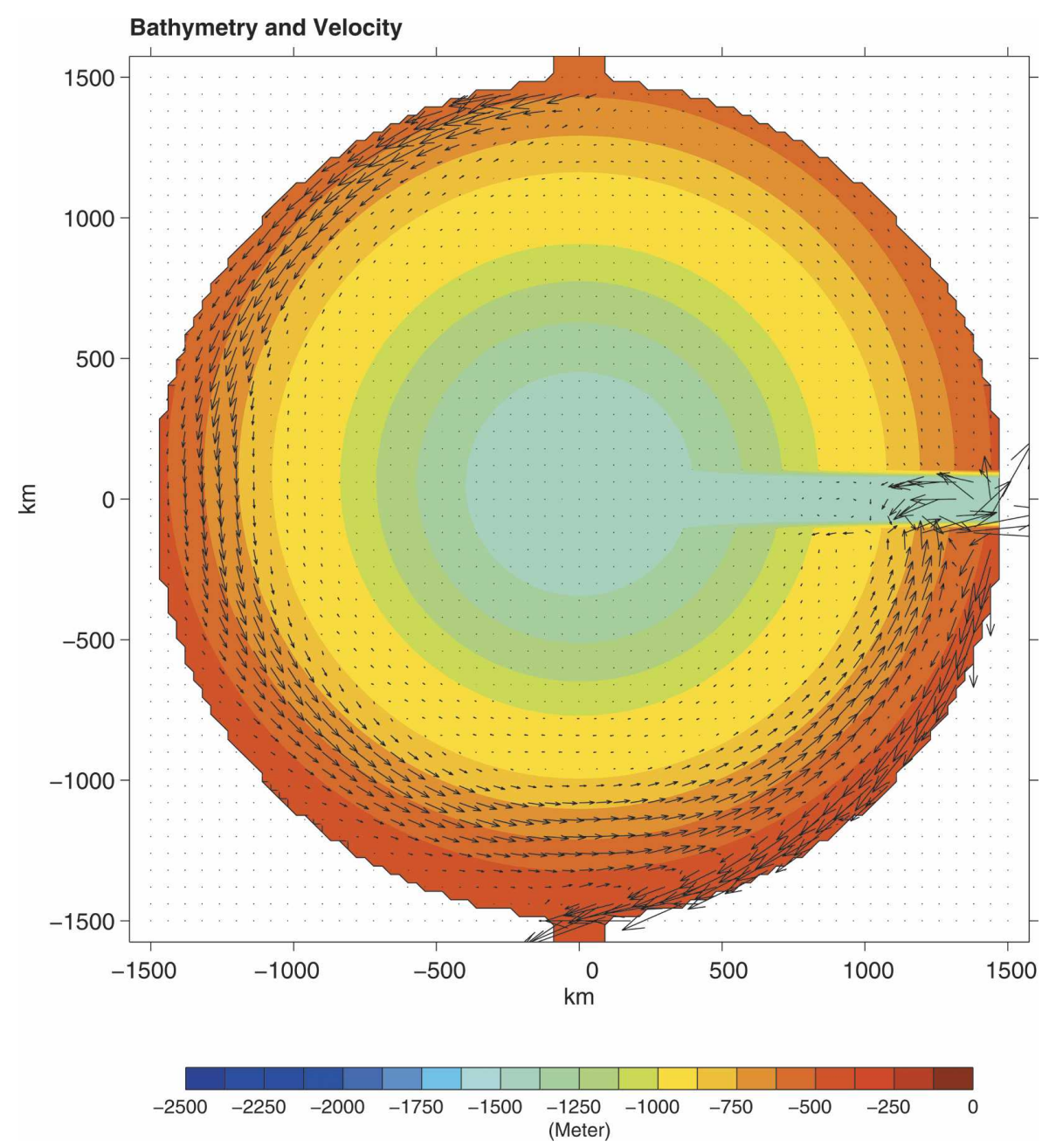

FIG. 18. As in Fig. 11 except with a trench. Note that the trench disrupts the PV contours and significantly changes the flow pathway.

The original motivation for this paper, as we stated earlier, is to search for a plausible mechanism that might explain the contradictory results generated by AOMIP models, which are all three-dimensional. What is the relevance of this two-dimensional study to a $3 \mathrm{D}$ flow? To start with, one must recognize that PV-integral constraint (7) applies not only to a barotropic model, but also to any density layer in a 3D circulation. The only difference is that $H_{i}$ in (7) is the isopycnal layer thickness at the $i$ th channel instead of the total sill depth. If the stratification at a channel is strong, the layer thickness of a particular water mass, say the Atlantic water, would be thin. The PV flux would be larger than a model that has a weaker stratification for the same amount of volume flux. Another important factor in a $3 \mathrm{D}$ model is the vertical resolution. A considerable portion of watermass exchange between the Arctic and subarctic oceans occurs through shallow passages. Even if the mass flux is small in one such passage, the PV flux can be very large. The PV flux through those shallow passages would be severely distorted in a model that has a coarse vertical resolution. Consequently, the basinwide circulation can be distorted by the same proportion through the PV-integral constraint (7). We have run an experiment in which $0.5 \mathrm{~Sv}$ of water is drawn from the Arctic Basin through a very shallow channel through the Canadian Archipalego. The PV budget becomes negative because of the large PV flux associated with this outflow. The circulation was flipped from the cyclonic one, shown in Fig. 3, to an anticyclonic one similar to the one shown in Fig. 4. In addition to lateral inflow and outflow, the diapycnal flux in a 3D circulation deserves a special attention. Yang and Price (2000) showed that the diapycnal flux, in a model with a no-slip boundary condition, does not contribute to the total PV integral 

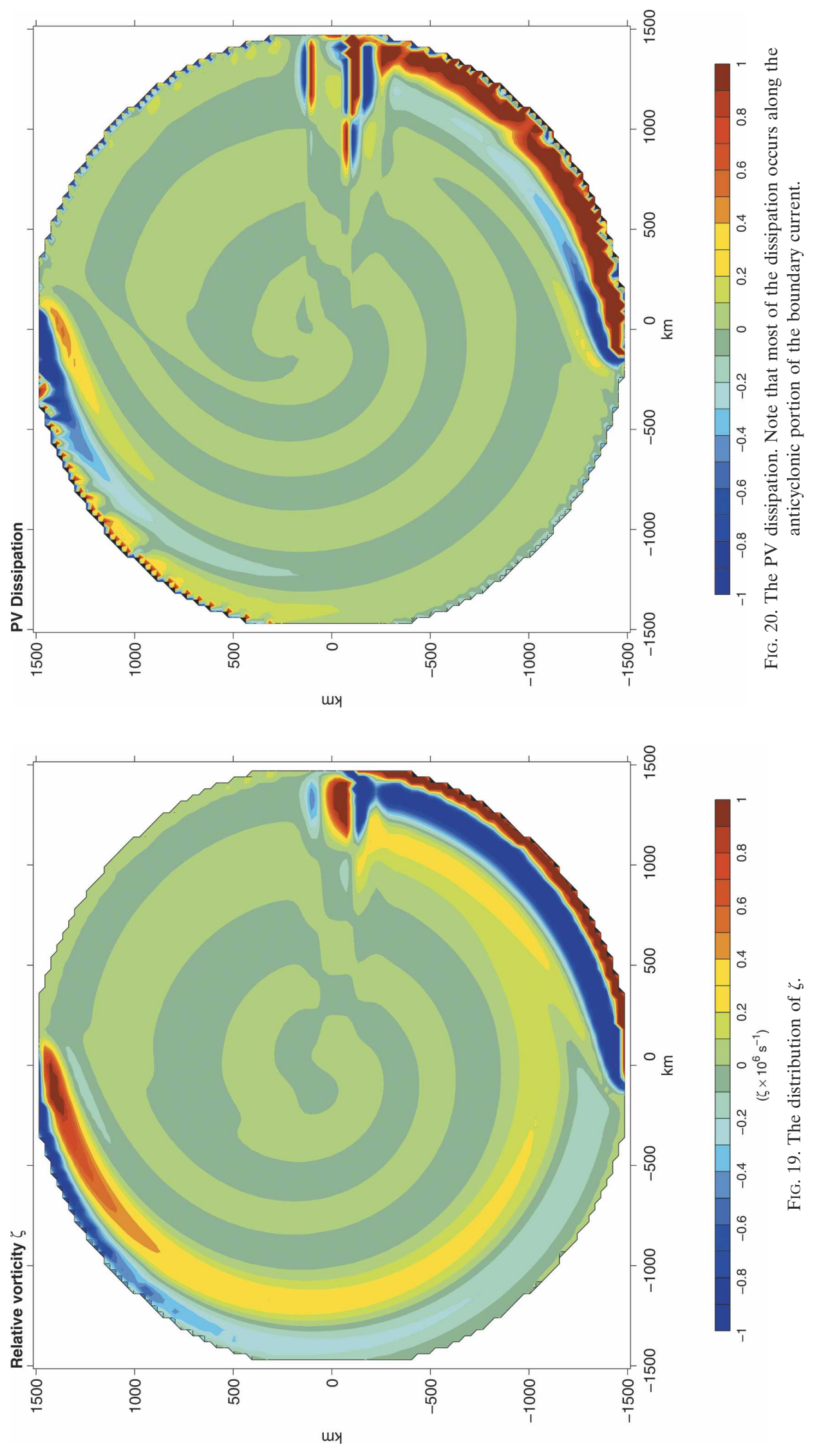
over the basin although it does affect the PV property locally [in a model with a free-slip boundary condition, the interfacial momentum flux can affect the PV integral through the last term in Eq. (6), although such an effect is generally small]. Imagine a scenario in which the inflow occurs in the upper ocean into the Arctic, the water mass cools, and descends into a denser lower layer inside the Arctic Basin. This type of watermass source does not affect the integral of the lower layer where the cooled water enters. Why? Yang and Price (2000) explained that a diapycnal flux $w^{*}(x, y)$ does two things to the PV budget: It advects PV into the lower layer just the same way as a lateral inflow or outflow does, but it also squashes (for the watermass source) or stretches (for the watermass sink) the vortex lines and produces an amount of PV that cancels exactly the one it advects into the layer. The net effect to the integral is zero. Although a $w^{*}(x, y)$ does not contribute to the integral, it does have a strong impact on the circulation. In the interior ocean, it forces a strong recirculation, known as the Stommel $\beta$ plume (Stommel 1982). But in the Arctic Ocean, the planetary $\beta$ is nearly zero, so a $\beta$ plume is likely to be highly nonlinear and dominated by eddies (e.g., Kida 2003). If the watermass conversion $w^{*}(x, y)$ occurs in the vicinity of shelf, topographic $\beta$ plumes will be established (e.g., Hallberg and Rhines 2000) and the rim current structure will be affected. However, the integral constraint (7) will remain unchanged.

We point out that the PV-integral constraint (7) is a two-way constraint. We have explored one side of this constraint by the imposing boundary condition of mass and PV fluxes and demand the dissipation process to work out its way to satisfy (7). The inflow and outflow in a global ocean model, for instance, must be determined by the model dynamics itself. Changes of the dissipations, such as enhanced bottom mixing or boundary layer diffusion, for instance, can result in changes of the flow between two basins. This is the other side of the PV-integral constraint (7) (J. Yang and J. F. Price 2005, unpublished manuscript). But this is less relevant to the goal of this study, which seeks to explain why Arctic Ocean models produce opposite circulation patterns.

Acknowledgments. This study was inspired originally by a seminar, in May 2004 at WHOI, presented by Dr. Greg Holloway, who showed the interesting AOMIP results. The invitation from Dr. Andrey Proshutinsky to attend and to present this study at the AOMIP workshop in June 2004 at GFDL allowed the author to learn more about the AOMIP results and to interact with AOMIP scientists. Those experiences have been crucial for this study. The author also thanks both Andrey and Greg, and other AOMIP scientists, for constructive discussions and their comments on this study. This study is supported by the NSF Office of Polar Programs (OPP0424074) and the NASA Cryospheric Science Program (NA17RJ1223).

\section{REFERENCES}

Aagaard, K., and P. Greisman, 1975: Towards new mass and heat budgets for the Arctic circulation. J. Geophys. Res., 80, 38213827.

- L. K. Coachman, and E. C. Carmack, 1981: On the halocline of the Arctic Ocean. Deep-Sea Res., 28, 529-545.

Hakkinen, S., and C. A. Geiger, 2000: Simulated low-frequency modes of circulation in the Arctic Ocean. J. Geophys. Res., 105, 6549-6564.

Hallberg, R., and P. B. Rhines, 2000: Boundary sources of potential vorticity in geophysical circulations. Developments in Geophysical Turbulence, R. M. Kerr and Y. Kimura, Eds., Kluwer, 51-65.

Holloway, G., 1992: Representing the topographic stress for largescale ocean models. J. Phys. Oceanogr., 22, 1003-1046.

Jones, E. P., B. Rudels, and L. G. Anderson, 1995: Deep waters of the Arctic Ocean: Origin and circulation. Deep-Sea Res., 42, 737-760.

Kawase, M., 1987: Establishment of deep ocean circulation driven by deep-water production. J. Phys. Oceanogr., 17, 2294-2317.

Kida, S., 2003: Eddy dynamics of $\beta$ plume. M.S. thesis, Department of Physical Oceanography, MIT-WHOI Joint Program in Oceanography, 84 pp.

Maslowski, W., B. Newton, P. Schlosser, A. Semtner, and D. Martinson, 2000: Modeling recent climate variability in the Arctic Ocean. Geophys. Res. Lett., 27, 3743-3746.

Nazarenko, L., G. Holloway, and N. Tausnev, 1998: Dynamics of transport of "Atlantic signature" in the Arctic Ocean. J. Geophys. Res., 103, 31 003-31 015.

Pedlosky, J., 1979: Geophysical Fluid Dynamics. Springer-Verlag, $624 \mathrm{pp}$.

_- 1996: Ocean Circulation Theory. Springer-Verlag, 453 pp.

Polyakov, I., 2001: An eddy parameterization based on maximum entropy production with application to modeling of the Arctic Ocean circulation. J. Phys. Oceanogr., 31, 2255-2270.

Proshutinsky, A. Y., and M. A. Johnson, 1997: Two circulation regimes of the wind-driven Arctic Ocean. J. Geophys. Res., 102, $12493-12514$.

—, and Coauthors, 2001: Multinational effort studies differences among Arctic Ocean models. Eos, Trans. Amer. Geophys. Union, 82, 637-644.

Rudels, B., and H. J. Friedrich, 2000: The transformations of Atlantic water in the Arctic Ocean and their significance for the freshwater water budget. The Freshwater Budget of the Arctic Ocean, E. L. Lewis, Eds., Kluwer, 503-532.

_ _ E. P. Jones, L. G. Anderson, and G. Kattner, 1994: On the intermediate depth waters of the Arctic Ocean. The Role of 
Polar Oceans in Shaping the Global Climate, O. M. Johannessen et al., Eds., Amer. Geophys. Union, 33-46.

Stommel, H., 1958: The abyssal circulation. Deep-Sea Res., 5, 8082.

_ 1982: Is the South Pacific helium-3 plume dynamically active? Earth Planet. Sci. Lett., 61, 63-67.

, and A. B. Arons, 1960a: On the abyssal circulation of the world ocean. I. Stationary planetary flow patterns on a sphere. Deep-Sea Res., 6, 140-154.
— and 1960b: On the abyssal circulation of the world ocean. II. An idealized model of circulation pattern and amplitude in oceanic basins. Deep-Sea Res., 6, 217-233.

Yang, J., 2003: On the importance of resolving the western boundary layer in ocean general circulation models. Ocean Modell., $\mathbf{5}, 357-379$

, and J. F. Price, 2000: Water-mass formation and potential vorticity balance in an abyssal ocean circulation. J. Mar. Res., 58, 789-808. 